\author{
Discussion Paper No. 2004/01
}

\title{
Spatial Decomposition of Inequality
}

\section{Anthony Shorrocks and Guanghua Wan*}

\author{
January 2004
}

\begin{abstract}
This paper reviews the theory and application of decomposition techniques in the context of spatial inequality. It establishes some new theoretical results with potentially wide applicability, and examines empirical evidence drawn from a large number of countries.
\end{abstract}

Keywords: inequality, index, decomposition

JEL classification: C43, D31, D63, R12

Copyright (C) UNU-WIDER 2004

* UNU-WIDER, Helsinki.

This is a revised version of a paper presented at the UNU-WIDER Conference Inequality, Poverty and Human Well-being, May 2003 in Helsinki. It has been prepared within the UNU-WIDER project on Spatial Disparities in Human Development, directed by Ravi Kanbur and Tony Venables, with Guanghua Wan.

UNU-WIDER gratefully acknowledges the financial contributions to the 2002-2003 research programme by the governments of Denmark (Royal Ministry of Foreign Affairs), Finland (Ministry for Foreign Affairs), Norway (Royal Ministry of Foreign Affairs), Sweden (Swedish International Development Cooperation Agency_Sida) and the United Kingdom (Department for International Development). 
The World Institute for Development Economics Research (WIDER) was established by the United Nations University (UNU) as its first research and training centre and started work in Helsinki, Finland in 1985. The Institute undertakes applied research and policy analysis on structural changes affecting the developing and transitional economies, provides a forum for the advocacy of policies leading to robust, equitable and environmentally sustainable growth, and promotes capacity strengthening and training in the field of economic and social policy-making. Work is carried out by staff researchers and visiting scholars in Helsinki and through networks of collaborating scholars and institutions around the world.

www.wider.unu.edu publications@wider.unu.edu

UNU World Institute for Development Economics Research (UNU-WIDER)

Katajanokanlaituri 6 B, 00160 Helsinki, Finland

The views expressed in this publication are those of the author(s). Publication does not imply endorsement by the Institute or the United Nations University, nor by the programme/project sponsors, of any of the views expressed.

ISSN 1609-5774

ISBN 92-9190-568-2 (printed publication)

ISBN 92-9190-569-0 (internet publication) 


\section{Introduction}

Spatial disparities in living standards have been the subject of a great deal of attention in recent years. At the global level there has been concern at the prospect of rising inequality in the world distribution of income and the extent to which this is fuelled by factors linked to globalization: see, for example, Milanovic (2002); Sala-i-Martin (2002); Bourguignon and Morrison (2002); Fischer (2003); Kremer and Maskin (2003). Similar concerns surface within individual countries, especially those countries where income inequality has been rising over time and where average incomes vary considerably across regions or provinces. In China, for example, unease with the growing disparity between the living standards in the coastal areas and the inland regions has prompted the Chinese government to launch a campaign to develop the western regions (Kanbur and Zhang 2003). The problem becomes a more intense political issue when spatial inequality is perceived to be related to discrimination against particular groups of citizens such as rural farmers (compared to urban residents), ethnic minorities concentrated in remote areas, migrants in certain districts, or religious groups in particular regions (eg. Muslims in Xinjiang Region in China).

The region of residence is not, of course, the only factor which accounts for differences in living standards: there are typically wide disparities in incomes within, as well as between, regions. Therefore, in order to appreciate the significance of geographical location it is necessary to have a method of separating out the contribution of the spatial factors. Many empirical studies of living standards make use of regional dummy variables, but the implications for the aggregate level or trend in inequality are rarely explored - at least in terms of the inequality measures commonly employed elsewhere.

The principal alternative procedure begins with an inequality value for the whole population which is broken down or 'decomposed' into contributions associated with different spatial dimensions. Typically the aggregate sample data are partitioned into a set of geographical regions or districts, and the data analysed in terms of the inequality observed within each of the regions, the inequality due to variations in average incomes across regions, and, in some cases, the inequality attributable to 'interactions' or 'overlaps' between the regional income distributions. Similar decomposition procedures are routinely applied to partitions into population subgroups defined according to a wide variety of other criteria, including gender, age, education level, and 
so on.

The aim of this paper is to review the current state of knowledge regarding inequality decomposition in a spatial context although, for the reasons explained above, the broad thrust of the comments also apply to many other types of decomposition by population subgroups. We begin in section 2 with a discussion of the foundations of the methodology for inequality decomposition. Section 3 outlines a number of general results on spatial decomposition which should be helpful in interpreting and assessing empirical evidence on the subject. Empirical evidence drawn from a number of country studies is then reviewed in the light of the theoretical insights. Section 5 concludes the paper.

\section{Theoretical Foundations of Spatial Decomposition of Inequality}

The analysis of spatial inequality typically begins with a measure of living standards or resources defined for a population of individuals or households. We follow common practice in referring to the measure of living standards as 'income', although it should be stressed at the outset that the income concept must be interpreted broadly to encompass not only home production and non-pecuniary income, but also all the advantages and disadvantages systematically associated with geographical location, including climate, regional price variations, local public good provision and environmental quality. In essence, the analysis assumes that individuals with the same income at different locations are equally well-off.

The formalities below are framed in terms of a (homogeneous, equally weighted) population of individuals represented by $N=\{1,2, \ldots, n\}$, with incomes given by the vector $\mathbf{y}=\left(y_{1}, \ldots, y_{n}\right)$ and mean income denoted by $\mu$. Income inequality is captured by an inequality index $I(\mathbf{y})$ which is assumed throughout to satisfy the following five basic properties: ${ }^{1}$

\footnotetext{
${ }^{1}$ These are all standard properties of measures of relative inequality. For more details see Silber (1999).
} 
(A1) symmetry (or anonymity);

(A2) the Pigou-Dalton principle of transfers (or strict Schur convexity): a mean-preserving progressive transfer reduces inequality; ${ }^{2}$

(A3) scale invariance (or homogeneity of degree zero);

(A4) replication invariance; and

(A5) zero normalisation: the minimum value of $I$ is zero (achieved when all incomes are identical).

The decomposition of inequality according to a partition of the aggregate population into geographical regions (or, more generally, into any set of mutually exclusive and exhaustive subgroups) is most often undertaken with one of the entropy indices popularised by Theil (1967, 1972) and later explored in more detail by Bourguignon (1979), Shorrocks (1980, 1984, 1988), Cowell and Kuga (1981), and Foster and Shneyerov (2000), amongst others. The single parameter entropy family may be written:

$$
\begin{aligned}
& E_{c}(\mathbf{y})=\frac{1}{c(c-1) n} \sum_{i \in N}\left\{\left(\frac{y_{i}}{\mu}\right)^{c}-1\right\}, \quad c \neq 0,1, \\
& E_{1}(\mathbf{y})=\frac{1}{n} \sum_{i \in N} \frac{y_{i}}{\mu} \ln \frac{y_{i}}{\mu}, \\
& E_{0}(\mathbf{y})=\frac{1}{n} \sum_{i \in N} \ln \frac{\mu}{y_{i}},
\end{aligned}
$$

or in the more condensed form:

$$
E_{c}(\mathbf{y})=\frac{1}{n} \sum_{i \in N} \varphi_{c}\left(y_{i} / \mu\right)
$$

where $\varphi_{c}(t)=\left(t^{c}-1\right) /[c(c-1)], \mathrm{c} \neq 0,1 ; \varphi_{1}(t)=t \ln t$; and $\varphi_{0}(t)=-\ln t$. Special cases include the Theil coefficient (corresponding to $c=1$ ), the mean logarithmic deviation $(c=0)$, and one half of the square of the coefficient of variation $(c=2)$.

The decomposition properties of this class of measures are best illustrated by considering the

\footnotetext{
2 Note that (A2) extends to situations in which frequencies $f_{1}, f_{2}, \ldots, f_{n}$ are attached to the income levels $y_{1}, y_{2}, \ldots, y_{n}$. Successive application of the principle of transfers implies that inequality will be reduced by any equalisation of two income levels which preserves the overall (weighted) mean income.
} 
index $E_{0}$ and by supposing that the set of individuals, $N$, is partitioned into $m$ proper subgroups $N_{k}(k=1,2, \ldots, m)$, with respective income vectors $\mathbf{y}^{k}$, mean incomes $\mu_{k}$, population sizes $n_{k}$, and population shares $v_{k}=n_{k} / n$. It will also be convenient to let $\overline{\mathbf{y}}^{k}$ denote the distribution obtained by replacing each income in the vector $\mathbf{y}^{k}$ with the subgroup mean $\mu_{k}$. Then

$$
\begin{aligned}
E_{0}(\mathbf{y}) & =E_{0}\left(\mathbf{y}^{1}, \mathbf{y}^{2}, \ldots, \mathbf{y}^{m}\right)=\frac{1}{n} \sum_{k=1}^{m} \sum_{i \in N_{k}} \ln \frac{\mu}{y_{i}} \\
& =\sum_{k=1}^{m} \frac{n_{k}}{n} \frac{1}{n_{k}} \sum_{i \in N_{k}} \ln \frac{\mu_{k}}{y_{i}}+\frac{1}{n} \sum_{k=1}^{m} \sum_{i \in N_{k}} \ln \frac{\mu}{\mu_{k}} \\
& =\sum_{k=1}^{m} v_{k} E_{0}\left(\mathbf{y}^{k}\right)+\sum_{k=1}^{m} v_{k} \ln \frac{\mu}{\mu_{k}}=\mathrm{W}+\mathrm{B}
\end{aligned}
$$

where

$$
\mathrm{W}=\sum_{k=1}^{m} v_{k} E_{0}\left(\mathbf{y}^{k}\right)
$$

is a weighted average of subgroup inequality values, traditionally referred to as the "withingroup' component of inequality; and

$$
\mathrm{B}=\sum_{k=1}^{m} v_{k} \ln \frac{\mu}{\mu_{k}}=E_{0}\left(\overline{\mathbf{y}}^{1}, \overline{\mathbf{y}}^{2}, \ldots, \overline{\mathbf{y}}^{m}\right)
$$

is the 'between-group' contribution to inequality, representing the level of inequality obtained by replacing the income of each person with the mean income of their respective subgroup. Thus — for the index $E_{0}$ at least — the overall level of inequality for a country can be expressed in an intuitively appealing fashion as an exact sum of the average inequality within regions and the inequality due purely to differences in average incomes between regions.

To appreciate the special attraction of the decomposition indicated by (3), it may be noted that for any inequality index $I($.) which satisfies properties (A1)-(A5), the aggregate level of inequality may be written

$$
I\left(\mathbf{y}^{1}, \mathbf{y}^{2}, \ldots, \mathbf{y}^{m}\right)=I\left(\mathbf{w}^{1} b_{1}, \mathbf{w}^{2} b_{2}, \ldots, \mathbf{w}^{m} b_{m}\right)=\hat{I}\left(\mathbf{w}^{1}, \mathbf{w}^{2}, \ldots, \mathbf{w}^{m}, \mathbf{b}\right),
$$

where $\mathbf{w}^{k}=\mathbf{y}^{k} / \mu_{k}$ indicates the vector of relative incomes within region $k$, and $\mathbf{b}=$ $\left(b^{1}, b^{2}, \ldots, b^{m}\right), b^{k}=\mu^{k} / \mu$, denotes the vector of relative mean incomes across regions. Equation (5) makes it clear that aggregate inequality in a country is completely accounted for by 
differences in relative income within regions (as captured in the vectors $\mathbf{w}^{k}$ ) and differences in relative mean income between regions (as captured by b). In this context, it is natural to regard the inequality contribution of $\mathbf{w}^{k}$ as the amount by which aggregate inequality falls if relative incomes in region $k$ are equalised, ceteris paribus; and the contribution of $\mathbf{b}$ as the amount by which aggregate inequality falls if regional mean income differences are eliminated, holding constant relative incomes within regions (ie by proportionately scaling incomes within each region until the regional mean matches the population value). For the index $E_{0}$, the within and components (4a) and (4b) conform to these interpretations. Furthermore, the values of the contributions are invariant to the order in which within- and between-group differences are eliminated.

Other inequality indices drawn from the entropy family (1) satisfy a similar decomposition equation given by

$$
E_{c}(\mathbf{y})=E_{c}\left(\mathbf{y}^{1}, \mathbf{y}^{2}, \ldots, \mathbf{y}^{m}\right)=\sum_{k=1}^{m} v_{k} b_{k}^{c} E_{c}\left(\mathbf{y}^{k}\right)+\sum_{k=1}^{m} v_{k} \varphi_{c}\left(b_{k}\right)=W+B
$$

which again leads to a natural interpretation in terms of the within- and between-group contributions to inequality:

$$
\begin{aligned}
& W=\sum_{k=1}^{m} v_{k} b_{k}^{c} E_{c}\left(\mathbf{y}^{k}\right) ; \\
& B=\sum_{k=1}^{m} v_{k} \varphi_{c}\left(b_{k}\right)=E_{c}\left(\overline{\mathbf{y}}^{1}, \overline{\mathbf{y}}^{2}, \ldots, \overline{\mathbf{y}}^{m}\right) .
\end{aligned}
$$

However, the decomposition provided by (6) is less satisfactory than that given by (3) for two reasons. First, while the within-region term remains a weighted sum of regional inequality values, the weights typically do not sum to one, unless $c=0$ or 1 . (The latter corresponds to the Theil coefficient, where the weights are given by the regional income shares). So it is usually wrong to interpret $W$ as the average level of inequality within regions. Secondly, the within-group component now depends both on within-group differences and (via the weights) on betweengroup differences. So any attempt to eliminate between-group variation along the lines suggested following equation (5) now has an indirect effect on the value of the within-group term. As a consequence the quantitative impact of eliminating within- and between-group variations is now 
sensitive to the order in which the factors are considered. ${ }^{3}$

The main appeal of the decomposition provided by (6) rests on the fact that the inequality indices are subgroup consistent in the following sense: holding regional mean incomes and population sizes fixed, an increase in inequality within each region must lead to an increase (or, at least, not a decrease) in inequality in the country as a whole. This property is evidently true for the entropy measures, since the ceteris paribus clause implies that the between-group term $B$ is constant in (6), and that the rise in regional inequality translates into a rise in the weighted sum of regional inequality values captured by the within-group component $W$.

Subgroup consistency is an intuitively appealing and relatively weak property satisfied by the Atkinson class of inequality measures as well as the Entropy family. ${ }^{4}$ However the Gini coefficient is not subgroup consistent, and therefore not amenable in general to a decomposition along the lines of (6). This has not discouraged many researchers from attempting to decompose the Gini index in specific contexts or using different principles. The method which most closely resembles (6) can be formulated by numbering the regions in order of increasing mean incomes, and by supposing that person $i$ occurs in the $i$ th position when the income distribution is written $\mathbf{y}=\left(\mathbf{y}^{1}, \mathbf{y}^{2}, \ldots, \mathbf{y}^{m}\right)$, and in position $r_{i}$ when all incomes are arranged in increasing order. The value of the Gini coefficient is then given by

$$
G(\mathbf{y})=\frac{2}{n^{2} \mu} \sum_{i \in N} r_{i}\left(y_{i}-\mu\right)
$$

and yields the decomposition equation (see, for example, Lambert and Aronson 1993)

\footnotetext{
3 This special property of $E_{0}$ corresponds to the 'path independence' property discussed by Foster and Shneyerov (2000). They observe that there are two ways of deriving $W$ and $B$. As discussed earlier, the first obtains the between-group $B$ contribution as the level of inequality which results after within-group inequality is eliminated by redistributing incomes equally within each region. $W$ is then taken as the residual. The second defines $W$ to be the level of inequality which results when inequalities between groups are eliminated by proportionally scaling each subgroup distribution until it has the same mean as the overall distribution, with the residual now taken to be $B$. The decomposition is said to be path-independent if these two methods produce identical results.
}

4 See Shorrocks (1988) for a more detailed discussion. 


$$
\begin{aligned}
G & =G\left(\mathbf{y}^{1}, \mathbf{y}^{2} \ldots, \mathbf{y}^{m}\right)=\frac{2}{n^{2} \mu} \sum_{k=1}^{m} \sum_{i \in N_{k}} r_{i}\left(y_{i}-\mu\right) \\
& =\frac{2}{n^{2} \mu} \sum_{k=1}^{m}\left\{\sum_{i \in N_{k}} i\left(y_{i}-\mu_{k}\right)+\sum_{i \in N_{k}} i\left(\mu_{k}-\mu\right)+\sum_{i \in N_{k}}\left(r_{i}-i\right) y_{i}\right\} \\
& =W+B+R
\end{aligned}
$$

where

$$
W=\frac{2}{n^{2} \mu} \sum_{k=1}^{m} \sum_{i \in N_{k}} i\left(y_{i}-\mu_{k}\right)=\sum_{k=1}^{m} v_{k}^{2} b_{k} G\left(\mathbf{y}^{k}\right)
$$

is a weighted sum of the within-group inequality values, and

$$
B=\frac{2}{n^{2} \mu} \sum_{k=1}^{m} \sum_{i \in N_{k}} i\left(\mu_{k}-\mu\right)=\sum_{k=1}^{m} b_{k} v_{k}\left[\sum_{j=1}^{k} v_{j}-\sum_{j=k}^{m} v_{j}\right]=G\left(\overline{\mathbf{y}}^{1}, \overline{\mathbf{y}}^{2}, \ldots, \overline{\mathbf{y}}^{m}\right)
$$

is the 'between-group component', representing the value of the Gini coefficient when the income of each individual is replaced by the mean income of the subgroup to which they belong. The final term, $R$, in equation (9) is a residual or 'interaction' effect which vanishes when the regional income ranges do not overlap (so that $r_{i}=i$, for all $i$ ), and is otherwise strictly positive.

When the regional income ranges are non-overlapping there is a very clear correspondence between the Gini decomposition (9) and the Entropy formulation (6); the only substantive difference is that the regional inequality weights are given by $v_{k} b_{k}^{c}$ in (6) and by $v_{k}^{2} b_{k}$ in (9). In this case also, it is natural to regard the ratio $B / G$ as a measure of the proportional contribution of regional income variation to total inequality, mimicking the analogous expression $B / E_{c}$ used in the context of Entropy indices. The situation becomes more problematic when the regional income ranges overlap, because the interaction term introduces a third, poorly specified, element into the decomposition equation (9). It is also important to note that (9) is not the only form of Gini decomposition on offer. Many other specifications have been suggested. The more recent proposals typically retain the division into within-, between-, and interaction terms, but differ in the formulae used for each of the components. ${ }^{5}$ In the absence of an obviously superior alternative, we proceed on the assumption that the between-group term $B$ defined in (10b)

\footnotetext{
${ }^{5}$ For early contributions, see Soltow (1960), Bhattacharya and Mahalanobis (1967), Rao (1969), Mangahas (1975) and Pyatt (1976). More recent developments include Silber (1989), Yitzhaki and Lerman (1991), Yitzhaki (1994) and Sastry and Kelkar (1994).
} 
expressed as a proportion of the overall Gini value captures what we mean by the importance of the contribution of average income variation by region to total inequality as measured by the Gini coefficient. ${ }^{6}$

Another departure from the traditional decomposition framework explores the implications of generalising the notion of average regional income to measures other than the mean. The idea dates back to Blackorby et al. (1981) but has recently been explored in greater detail by Foster and Schneyerov (2000). In this framework the between-group term is constructed by replacing the income of each individual with a suitably defined representative income level for the region. Employing representative income levels other than the mean expands the set of inequality indices that have simple and attractive decomposition properties. This opens up some interesting lines for future research, but since the empirical applications have not yet seen the light of day they are not pursued further in this paper.

\section{Some General Theoretical Results}

Despite the widespread use of decomposition techniques, little attention has been given in the past to establishing general decomposition results. The range of indices considered in the last section, combined with the possibility of alternative decomposition specifications, may have made it seem difficult to draw general conclusions about the way in which spatial factors impact on inequality. This turns out to be unduly pessimistic. The results below apply to any inequality index $I(\cdot)$ which satisfies (A1)-(A5), and document the properties of a 'between-group term' $B$ defined by

$$
B=I\left(\overline{\mathbf{y}}^{1}, \overline{\mathbf{y}}^{2}, \ldots, \overline{\mathbf{y}}^{m}\right),
$$

in accordance with (4b), (7) and (10b) above.

Consider first the range of values for $B$ and how the value compares with the overall inequality

\footnotetext{
6 Note however that eliminating between-group inequality by scaling incomes within each subgroup until they match the population average will in general not only affect the within group term (as with most Entropy indices) but also the interaction component.
} 
value $I=I\left(\mathbf{y}^{1}, \mathbf{y}^{2}, \ldots, \mathbf{y}^{m}\right)$. Intuitively, when only one group is identified (i.e. $m=1$ ) then average incomes do not vary across regions and $B$ must be zero. At the other end of the scale, if the number of regions is the same as the size of the population (i.e. $m=n$ ), then each region contains a single observation and $B$ must equal $I$. It is also reasonable to expect that these two cases represent the minimum and maximum values that $B$ can take, so that:

Proposition 1: (a) $0 \leq B \leq I$; (b) $B=0$ if $m=1$; (c) $B=I$ if $m=n$.

To establish Proposition 1, note that (b) and (c) are both immediate consequences of the definition of $B$ given by (11), because $B$ is the inequality value obtained by replacing the income of each person by their corresponding regional mean. In addition, we have $B \geq 0$ because the index $I($.) is always non-negative (by A5); and $B \leq I$ because the 'regionally equalised' distribution $\left(\overline{\mathbf{y}}^{1}, \overline{\mathbf{y}}^{2}, \ldots, \overline{\mathbf{y}}^{m}\right)$ is obtained from the original distribution $\left(\mathbf{y}^{1}, \mathbf{y}^{2}, \ldots, \mathbf{y}^{m}\right)$ by applying an equalizing (and hence inequality reducing, by A2) procedure to each region in turn.

The argument in support of Proposition 1 also suggests a non-decreasing relationship between the number of regions and the magnitude of the between-group term. An increase in the number of regions will increase the opportunities for differentiating between the regional mean values used in the calculation of $B$, thereby causing the value of $B$ to rise. This is most easily seen by reversing the question and asking about the consequences of reducing the number of regions via a merger between two regions. The impact on the value of $B$ is equivalent to that of a meanpreserving equalization of the two subgroup income levels which, by the principle of transfers (A2), cannot increase the value of $B$. Hence:

Proposition 2: The value of $B$ does not increase if any two regions are combined. ${ }^{7}$

The 'finer partition' characterisation in Proposition 2 is one way of capturing the idea that $B$ increases monotonically with $m$. Another possible interpretation is that the between-group term is larger on average when more regions are identified, in other words:

Proposition 3: The expected value of $B$ increases with $m .^{8}$

\footnotetext{
${ }^{7}$ Note that successive application of Proposition 2 allows Proposition 1(a) to be derived from Proposition 1(b) and 1(c).

${ }^{8}$ We are indebted to Ravi Kanbur for suggesting that this result may hold.
} 
This proposal is still not well formulated, since it is not clear how the expectation is to be taken over the space of partitions and over the allocation of individuals to subgroups. For example, each of the partitions into $m$ regions may be treated as equally likely, or they may be assigned a probability corresponding to the likelihood that this partition is observed when $n$ individuals are randomly distributed across $m$ categories.

While a formal proof of Proposition 3 is beyond the scope of this paper, intuition suggests that the result must hold under a variety of interpretations for the following reason. For a fixed-size population, an increase in the number of regions causes the average size to fall, so the distribution shifts towards smaller sized regions. But, as the mean value of smaller samples exhibits greater variability, the net effect is an increase in the expected inequality value captured in the between-group term (11).

The shift towards smaller sized classes can be formalised when $n$ individuals are randomly allocated across $m$ regions, each containing at least one person. The probability that a region contains $r+1$ members $(r \geq 0)$ is then given by the multinomial value

$$
\pi_{r+1}(m)=\frac{(n-m) !}{r !(n-m-r) !}\left(\frac{1}{m}\right)^{r}\left(\frac{m-1}{m}\right)^{n-m-r}, \quad r=0, \ldots, n-m,
$$

from which it follows that

$$
\pi_{r+2}(m) / \pi_{r+1}(m)=\frac{n-m-r}{r+1} \frac{1}{m-1}=\frac{n-r-1}{(r+1)(m-1)}+\frac{1}{r+1} \geq \pi_{r+2}(m+1) / \pi_{r+1}(m+1) .
$$

In other words, the frequency of larger regions falls off faster as the number of regions increases. According to Proposition B.1 of Marshall and Olkin (1979, p.129), condition (13) ensures that $\pi(m)$ is majorised by (ie Lorenz dominates) $\pi(m+1)$ for all $m$, so that

(14) $\quad \sum_{r=0}^{s} \pi_{r}(m) \geq \sum_{r=0}^{s} \pi_{r}(m+1)$, for all $m$ and all $s$.

This is the formal sense in which the distribution of regions shifts towards smaller sizes as the number of regions increases. A similar condition is likely to hold when alternative methods are used to allocate a given population of individuals to a given number of groups. 
Let us now fix the partition level $(m)$, the sizes of regions $\left\{n_{1}, \ldots, n_{m}\right\}$, and the overall income distribution $\mathbf{y}=\left(y_{1}, \ldots, y_{n}\right)$, and consider what can be said about the way in which $B$ depends on the allocation of individuals (and hence incomes) across the regions. The following two observations follow immediately from the definition (11) of the between-group term.

Proposition 4: (a) if the distribution of income is the same in each region then $B=0$;

(b) if the regional mean incomes are all equal then $B=0$.

Note that the prerequisite in part (b) of Proposition 4 is significantly weaker than the corresponding requirement in part (a).

Proposition 4(a) refers to the situation in which the subgroup distributions overlap to the greatest possible extent. It seems plausible to suppose that a reduction in the degree of overlap will translate into a smaller between-group term, but the precise relationship is difficult to formalise given that a reduction in overlap between two subgroups may not necessarily cause the subgroup means to move apart. At the other end of the scale, however, it is possible to establish that if the regional income ranges (strictly) overlap then the between-group term is not a maximum, and hence:

Proposition 5: $B$ is a maximum only if the regional income ranges do not overlap.

The argument is as follows. Suppose that regions $k$ and $\ell$ have strictly overlapping distributions and that $\mu_{k} \leq \mu_{\ell}$ Choose $i \in N_{k}$ and $j \in N_{\ell}$ such that $y_{i}>y_{j}$. Then swapping the incomes $y_{i}$ and $y_{j}$ between the two regions raises the mean income in the 'more affluent' region $\ell$, so the switch corresponds to a regressive Pigon-Dalton transfer between the two subgroup income levels which, by appeal to (A2), must increase the inequality value represented by $B$.

Note that disjoint income intervals is a necessary condition for $B$ to be a maximum, but it is not sufficient unless all subgroups have equal size. In other cases, it is necessary to consider how the different sized groups should be positioned in the income range. Drawing on the lessons of the similar exercise in Davies and Shorrocks (1989), it seems likely that the larger groups will be positioned at the centre of the income distribution, and that the subgroup sizes will decline 
monotonically towards each tail. ${ }^{9}$

\section{Empirical Evidence}

There is now a large empirical literature on inequality decomposition by population subgroups defined in terms of spatial location. The number of studies which report inequality decompositions using non-spatial elements (education, age, gender, etc.) is even greater. Given the focus of this paper, attention is confined here to spatial applications. But, as in the previous sections, the conclusions may well apply also in the non-spatial context.

The type of questions we will attempt to address are as follows: Do any general patterns or conclusions emerge from the empirical literature? Is any empirical regularity observed in the relationship between the number of groups and the magnitude of the share of the between-group component? To what extent do the decomposition results depend on the measure of inequality? Are the results sensitive to the 'income' variable used in the analysis?

Most empirical spatial decomposition studies use either the mean logarithmic deviation index $E_{0}$ or the Theil Index $E_{1}$. Tables $1 \mathrm{~A}$ and $1 \mathrm{~B}$ summarise the results obtained from applying the decomposition of $E_{0}$ to many countries and points of time. Given the differences in sample size, choice of income variable, selection of regions, etc. reliable general conclusions are hard to draw. For this reason, it is safer to use the term 'observation' rather than finding or conclusion.

Tables $1 \mathrm{~A}$ and $1 \mathrm{~B}$ here

\section{Observation 1: The magnitude of the between-group component.}

As is typical of most subgroup decompositions, the between-group component is small relative to the within-group component except in the case of urban-rural divide (see Observation 2). This is particularly true when earnings data are used (see Observation 3).

\footnotetext{
9 Interestingly, Davies and Shorrocks (1989) show that the between-group component in the Gini decomposition can closely approximate total inequality with a relatively small number of subgroups, as long as the subgroup income ranges are non-overlapping and the group sizes are chosen optimally.
} 
Excluding these two sets of circumstances, the share of the within-group component averages $12 \%$ with a minimum of $0 \%$ and a maximum of $51 \%$.

Some have concluded from this type of evidence that space or location is a relatively unimportant explanation of inequality (see, for example, Cowell and Jenkins (1995) ). However, before this conclusion is drawn, it should be noted that, as a determinant of inequality, space is poorly defined. Spatial location is often not of interest itself, but rather because of its association with many other important influences such as natural resources, weather conditions, cultural traditions, and even institutional arrangements. While some of these factors may contribute positively to the between-group component, uniform institutional arrangements such as nationwide policies are likely to make a negative contribution. Current procedures assign all of these factors to location without trying to disentangle the associated influences. The estimated between-group component cannot therefore be taken as a measure of the spatial contribution unless and until the definition of space is clarified. Furthermore, caution needs to be exercised when drawing policy implications from the empirical evidence. As noted by Kanbur (2002), if space is related to race or ethnicity, a small between-group component may not accurately reflect the significance of space as a determinant of inequality.

\section{Observation 2: The rural-urban divide.}

The rural-urban division seems always to produce a much larger between-group component. It ranges from $9 \%$ for Greece to as much as $78 \%$ for China. This latter result was obtained using regional level rather than household level data for China, and is therefore not strictly comparable. However, household-level data for China still yields a between-group component share of almost $38 \%$ (Lee 2000). Overall, the studies applying a rural-urban split to household data yield an average between-group component of $19.6 \%$, almost $8 \%$ higher than the average reported in Observation 1 above.

The between-group component depends on both the number of subgroups and differences in group means (or representative group values). Empirical evidence suggests that differences in means are the more important of these two factors, because the rural-urban distinction employs the minimum number of subgroups. Other spatially defined decompositions often involve a much larger number of groups but produces a smaller within-group component, as is evident from the Table 1A data for China, Indonesia and the Philippines. 
What is the reason for the relatively large between-group component for the rural-urban divide? As mentioned earlier, the cause may well lie in the inability of current decomposition techniques to control for other variables. Lower prices and/or availability of home produced food in rural areas may not be fully reflected in the data on living standards. Furthermore, the ruralurban divide in developing countries is often associated with other differences linked to the provision of infrastructure, the development of capital markets, education, health care, and so on. Controlling for these effects is likely to lead to smaller between-group components for the pure spatial effect in the context of the rural-urban divide.

In China, the rural-urban separation has been largely institutionalized. This separation results in dramatic differences in employment opportunities, education, infrastructure, health care, and access to capital and technology. Further the separation also causes different returns to these factors, because the markets are not integrated. Added together, it is not difficult to understand the reasons for the very large share of the between-group component in China.

\section{Observation 3: Alternative income concepts}

The data in Table 1A refer to income or consumption. Table 1B reports similar data for earnings in one country (the UK). The percentage share of the between-group component turns out to be much lower, ranging from $1 \%$ to $12 \%$, with an average of $4.8 \%$. Interestingly, total inequality in earnings is not smaller than inequality of income or consumption, which suggests that there is considerable wage differentials across occupations or sectors, but relatively little variation in occupational wages across locations. While it is dangerous to extrapolate from data from a single country, the same result may apply to other market economies where there are no constraints to migration, and where returns to labour and human capital are more or less equalized across space. Collective bargaining, the strength of labour unions and national wage setting policies may also be influential.

Equal factor returns are not sufficient, of course, to produce a negligible between-group component in decompositions of earnings inequality: the employee structure of the workforce must also be similar across space. It would therefore be useful to decompose the within-group component further into a 'returns' effect and a 'workforce structure' effect, the former reflecting market development and migration, and the latter reflecting industrial structure. 
Although the distribution of consumption is known to be more equal than income, this does not appear to carry over to the proportional contribution of the between-group component of income inequality. For example the between-group component is relatively small for the income observations from Finland and Switzerland.

\section{Observation 4: Alternative measures of inequality}

A number of empirical studies report decomposition results based on different inequality indices, enabling us to compare the percentage share of the within-group component across indices. The correlation coefficients are presented in Table 2. The correlation amongst the various Entropy measures tends to be quite high; the correlation with the Gini values are somewhat lower. Overall, Table 2 suggests that the results obtained using one index should broadly carry over to other indices.

\section{Table 2 here}

\section{Observation 5: Country coverage.}

Although spatial decompositions exist for the UK, USA, and some other developed countries, results on regional inequality are dominated by developing country evidence. The limited number of studies for developed countries does not imply that spatial inequality is not of interest in the developed world. However, the greater attention in developing or transition economies may reflect the fact that weak market forces, or restrictions on factor mobility, prevent returns to income generating factors from converging. In the search for explanations for the existence of spatial inequality, it may be useful compare the values of the between-group component obtained for developed and developing countries.

\section{Observation 6: Spatial price variations.}

The majority of empirical studies reported in Table 1 do not adjust for spatial price differences, although such differences exist and may substantially change the results for both developing countries such as China (see Wan 2001) and free market economies such as the US (see Ram 1992). Price levels are often correlated with living standards, so adjusting for spatial price differences will tend to lower the between-group term in the spatial decomposition while 
not altering inequality within regions (although the within-group component may be affected in an unpredictable fashion due to a change in the weights). Thus, despite its relatively small value (see Observation 1 above), the reported share of the between-group component is likely to be exaggerated, particularly in countries with a big land mass and underdeveloped markets.

\section{Observation 7: The number of subgroups and the size of the between-group component.}

As discussed in Section 3, the between-group component is expected to rise as the number of groups increases. To examine the empirical evidence, Figures 1-4 present scatter plots of the share of the between-group component against the number of subgroups. ${ }^{10}$ The graphs do not show any obvious positive relationship; if anything, the reverse appears to be the case. This apparent conflict with the theoretical predictions is not completely surprising, however, because other factors are not held constant. In particular, comparability is compromised if different criteria are used to group the sample observations. This is easily detected in the results for China, Indonesia and the Philippines. In the relevant studies, the samples were divided into urban-rural areas as well as into regions. In doing so, the number of subgroups increases from 2 to 26 or 27 for Indonesia ( 2 to 13 for the Philippines, 2 to 3 or 26 for China), but the between-groupcomponent falls in most cases. This clearly indicates the dominant impact of differences in living standards between rural and urban residents, which more than offsets the contribution of the number of subgroups.

Figures 1 - 4 here

To examine properly the positive relationship between the number of subgroups and the size of the between-group component requires progressive aggregation of subgroups. This has been done by Elbers et al. (2002) for Ecuador, Madagascar and Mozambique ${ }^{11}$ and by Cheng (1996) for China. Results from Elbers et al. indicate small increases in the between-group component, even if the number of groups increases dramatically. Using consumption data, Cheng (1996) reports a rise in the between-group component from $28 \%$ to $37 \%$ when the number of groups

\footnotetext{
${ }^{10}$ To assist the visual presentation, observations with more than 27 subgroups are excluded: these will be discussed later. Also excluded are the results for the rural-urban divide in China, as they are treated as outliers.

11 These observations were excluded from Figures 1-4.
} 
increases from 3 to 26 . Using data on the gross value of industrial and agricultural outputs (GVIAO), the corresponding change is from $39 \%$ to $51 \%$.

To explore further the relationship between the number of subgroups and the share of the between-group component, we employed the regression model:

$$
S=f(m, D)
$$

where $S$ is the share of the between-group component, $m$ is the number of subgroups, and $D$ refers to a set of dummy variables to control for different income concepts, different inequality measures, and the rural-urban division versus other spatial partitions. To allow for possible nonlinearities, the model specification takes the Box-Cox form. The standard linear model always produced an insignificant parameter for the core variable $m$, but a simple $\chi^{2}$ test suggested preference for the Box-Cox model.

Estimation results with the Box-Cox model are reported In Table 3, with $E_{0}$ as the reference index. The results indicate that (a) the size of the between-group component is positively related to the number of subgroups at any conventional level of statistical significance; (b) increasing the number of groups by one leads on average to an increase of 0.07 in the percentage share of the between-group component; (c) earnings data tends to yield a smaller between-group component, (d) the urban-rural partition gives a larger between-group component; and (e) the Gini coefficient produces larger shares for the between-group component compared to other indices.

Table 3 here

In summary, this section has attempted to present empirical results that may help future research, both empirical and theoretical. Many questions have been raised which require attention from theorists and empirical researchers. Of particular importance are the appropriate measure of spatial proximity; the relationship between the number of groups and the between-group component; the use of subgroup means or alternative measures of representative incomes; and the choice of inequality index. 


\section{Concluding remarks}

This paper has ranged over a number of theoretical and empirical issues linked to decomposition analysis in a spatial context. Various other issues have yet to be explored. For example, with the exception of Kanbur and Zhang (1999), there is little in the way of empirical literature on the time profile of the within or between-group component. Availability of data is an obstacle here. Nevertheless, a time profile would enrich the empirical literature by adding a dynamic dimension to the studies of spatial inequality decomposition.

More could be done also to link inequality decomposition to the recent extensive literature on growth. In particular, examination of the pattern of the between-group component may be a better way of studying convergence than the commonly-used sigma convergence approach.

Another set of issues requiring attention concern the underlying factors which ultimately contribute to spatial inequality, factors like economic geography (climate, natural resources), policy regimes, market orientation, and related socio-economic variables. Whether or not spatial differences persist or whither away over time is perhaps influenced most by the freedom to migrate, both within countries and internationally. The extent to which labour migration can help reduce regional disparities is an important question with obvious policy significance. 


\section{References}

Akita, T., R. Lukman, A. Rizal and Y. Yamada: Inequality in the Distribution of Household Expenditures in Indonesia: A Theil Decomposition Analysis, Developing Economies. June 1999; 37(2): 197-221.

Balisacan, A. and N. Fuwa: Is Spatial Inequality Increasing in the Philippines, Paper presented at the WIDER Conference on Inequality in Asia, 28-29 March 2003, Tokyo.

Blackorby, C., D. Donaldson and M. Auersperg: A New Procedure for the Measurement of Inequality Within and Among Population Subgroups, Canadian Journal of Economics. 1981; 14: 665-685.

Bourguignon, F. and C. Morrison: Inequality among World Citizens: 1820-1992, American Economic Review. 2002; 92(4): 727-744.

Cheng, Y.: A Decomposition Analysis of Income Inequality of Chinese Rural Households, China Economic Review. Fall 1996; 7(2): 155-67

Cowell, F.A. and S.P. Jenkins: How Much Inequality Can We Explain? A Methodology and an Application to the United States, Economic Journal. March 1995; 105(429): 421-30

Davies, J. B., and A. F. Shorrocks: Optimal grouping of income and wealth data, Journal of Econometrics, 1989; 42, 97-108.

Deutsch, J. and J. Silber: Inequality Decomposition by Population Subgroups and the Analysis of Interdistributional Inequality, in J. Silber, ed. Handbook of income inequality measurement. Boston; Dordrecht and London: Kluwer Academic, 1999; 363-97.

Dickey, H.: Regional Earnings Inequality in Great Britain: A Decomposition Analysis, Regional Studies. October 2001; 35(7): 605-12.

Elbers, C., P. Lanjouw, J. Mistiase, B. Ozler. and K. Simler: Are Neighbours Unequal? Estimating Local Inequality in Three Developing Countries, Paper presented at the WIDERCornell-LSE Conference on Spatial Inequality and Development, LSE, 28-30 June 2002.

Ernst, C., M. Gerfin and R. E. Leu: Inequality Trends in the Swiss Income Distribution, Swiss Journal of Economics and Statistics. September 2000; 136(3): 289-305.

Fischer S.: Globalization and Its Challenges, American Economic Review. 2003; 93(2): 1-30.

Foster, J.E. and A.A. Shneyerov: Path Independent Inequality Measures, Journal of Economic Theory. April 2000; 91(2): 199-222.

Gray, D., J.A. Mills, and S. Zandvakili: New Perspectives on Canadian National and Provincial 
Income Inequality, Paper presented at the UNU-WIDER Conference on Inequality, Poverty and Human Well-Being, Helsinki, 30-31 May 2003

Jenkins, S. P.: Accounting for Inequality Trends: Decomposition Analyses for the UK, 1971-86, Economica. February 1995; 62(245): 29-63

Kanbur, R.: Notes on the Policy Significance of Inequality Decompositions, unpublished paper. July, 2002.

Kanbur, R. and X. Zhang: Which Regional Inequality? The Evolution of Rural-Urban and Inland-Coastal Inequality in China from 1983 to 1995, Journal of Comparative Economics. December 1999; 27(4): 686-701.

Kanhur, R. and X. Zhang: Fifty Years of Regional Inequality in China: A Journey through Central Planning, Reform and Openness, Paper presented at the UNU-WIDER Conference on Spatial Inequality in Asia, Tokyo, 28-29 March 2003.

Kremer, M. and E. Maskin: Globalization and Inequality, unpublished manuscript, Harvard University. 2003.

Lambert, P.J. and J. R.Aronson: Inequality Decomposition Analysis and the Gini Coefficient Revisited, Economic Journal. September 1993; 103(420): 1221-27

Lee, J.: Changes in the Source of China's Regional Inequality, China Economic Review. 2000; 11(3): 232-45.

Loikkanen, H. A., M. Riihelä and R. Sullström: Regional income convergence and inequality in boom and bust: Results from micro data in Finland 1971-1998, and especially during the 1990s. Paper prepared for the meeting of the ESRC Urban and Regional Economics Seminar Group, 1-3 July, 2002, University of Central Lancashire, UK.

Mangahas, M.: Income Inequality in the Philippines: a Decomposition Analysis. World Employment Programme Working Paper No. 12, Geneva, ILO, 1975.

Marshall, A.W. and I. Olkin (1979): Inequalities: Theory of Majorization and its Applications. New York: Academic Press.

Mehran, F.: Decomposition of the Gini Index, A Statistical Analysis of Income Inequality. Income Distribution and Employment Program Working Paper, Geneva, ILO, 1974.

Meagher, G.A. and P. B. Dixon: Analyzing Income Distribution in Australia, Economic Record. December 1986; 62(179): 427-41.

Milanovic, B.: True World Income Distribution, 1988 and 1993: First Calculation Based on Household Surveys Alone, Economic Journal, January 2002, 112, 51-92.

Milanovic, B. and S. Yitzhaki: Decomposing World Income Distribution: Does the World Have 
a Middle Class? Review of Income and Wealth. June 2002; 48(2): 155-78.

Mishra, P. and A. Parikh: Household Consumer Expenditure Inequalities in India: A Decomposition Analysis, Review of Income and Wealth. June 1992; 38(2): 225-36.

Mookherjee, D. and A. F. Shorrocks: A Decomposition Analysis of the Trend in UK Income Inequality, Economic Journal. December 1982; 92(368): 886-902

Parker, S. C.: The Inequality of Employment and Self-Employment Incomes: A Decomposition Analysis for the U.K., Review of Income and Wealth. June 1999; 45(2): 263-74

Pyatt, G.C.: On the Interpretation and Disaggregation of Gini Coefficients, Economic Journal. 1976; 86: 243-255.

Ram, R.: Interstate Income Inequality in the United States: Measurement, Modelling and Some Characteristics, Review of Income and Wealth. March 1992; 38(1): 39-48.

Sala-i-Martin, X.: The Disturbing "Rise" of Global Income Inequality, NBER Working Paper 8904, April 2002.

Sastry, D. V. S. and U. R. Kelkar: Note on the Decomposition of Gini Inequality, Review of Economics and Statistics. August 1994; 76(3): 584-86

Shorrocks, A. F.: The Class of Additively Decomposable Inequality Measures, Econometrica. 1980; 48: 613-625.

Shorrocks, A. F.: Inequality Decomposition by Population Subgroups, Econometrica. November 1984; 52(6): 1369-85

Shorrocks, A. F.: Aggregation Issues in Inequality Measurement, in Eichhorn, W. (ed.). Measurement in Economics, Physica-Verlag. 1988, 429-451.

Silber, J.: Factor Components, Population Subgroups and the Computation of the Gini Index of Inequality, Review of Economics and Statistics. February 1989; 71(1): 107-15

Silber, J. (ed.): Handbook of income inequality measurement. Boston; Dordrecht and London: Kluwer Academic, 1999.

Tadjoeddin M., W. Suharyo and S. Mishra: Aspiration To Inequality: Regional Disparity And Centre-Regional Conflicts In Indonesia, Paper presented at the WIDER Conference on Inequality in Asia, 28-29 March 2003, Tokyo.

Theil, H.: Economics and Information Theory. Amsterdam: North Holland Publishing Co., 1967.

Theil, H.: Statistical Decomposition Analysis. Amsterdam: North Holland Publishing Co., 1972.

Tsakloglou, P.: Aspects of Inequality in Greece: Measurement, Decomposition and Intertemporal Change: 1974, 1982, Journal of Development Economics. February 1993; 40(1): 53-74 
Vanderpuve, O. J.: Spatial Inequality and Polarization in Ghana, 1987-99. Paper presented at the WIDER Conference on Spatial Inequality in Africa, Oxford University, 21-22 September 2002 .

Wan, G.H.: Changes in Regional Inequality in Rural China: Decomposing the Gini Index by Income Sources, Australian Journal of Agricultural and Resource Economics. 2001; 45(3): 361-82.

Yemtsov, R.: Quo Vadis: Inequality and Poverty Dynamics Across Russian Regions in 19942000, Paper presented at the WIDER-Cornell-LSE Conference on Spatial Inequality and Development, LSE, 28-30 June 2002.

Yitzhaki, S. and R. I. Lerman: Income Stratification and Income Inequality, Review of Income and Wealth. September 1991; 37(3): 313-29. 
Table 1A: Spatial decomposition of $\mathrm{E}_{0}$ : income or expenditure

\begin{tabular}{|c|c|c|c|c|c|c|c|c|}
\hline Country & $\begin{array}{l}\text { No. of } \\
\text { groups }\end{array}$ & Year & $\begin{array}{c}\text { Total } \\
\text { inequality }\end{array}$ & $\begin{array}{c}\text { Between } \\
\%\end{array}$ & $\begin{array}{c}\text { Within } \\
\%\end{array}$ & Category & Source & Remarks \\
\hline \multirow[t]{7}{*}{ Canada } & 9 & 1991 & 0.264 & 1.9 & 98.1 & province & \multirow{7}{*}{$\begin{array}{l}\text { Gray et al. } \\
(2003)\end{array}$} & \multirow{7}{*}{$\begin{array}{l}\text { survey data on } \\
\text { total household } \\
\text { income }\end{array}$} \\
\hline & 9 & 1992 & 0.272 & 1.5 & 98.5 & & & \\
\hline & 9 & 1993 & 0.273 & 1.8 & 98.2 & & & \\
\hline & 9 & 1994 & 0.272 & 1.5 & 98.5 & & & \\
\hline & 9 & 1995 & 0.272 & 1.8 & 98.2 & & & \\
\hline & 9 & 1996 & 0.281 & 1.8 & 98.2 & & & \\
\hline & 9 & 1997 & 0.312 & 1.6 & 98.4 & & & \\
\hline \multirow[t]{13}{*}{ China } & 2 & 1983 & 0.079 & 6.5 & 93.6 & coast/inland & \multirow{13}{*}{$\begin{array}{l}\text { Kanbur and } \\
\text { Zhang (1999) }\end{array}$} & \multirow{13}{*}{$\begin{array}{l}\text { regional data on } \\
\text { per capita } \\
\text { consumption } \\
\text { expenditure }\end{array}$} \\
\hline & 2 & 1984 & 0.076 & 6.6 & 93.5 & & & \\
\hline & 2 & 1985 & 0.075 & 6.0 & 94.0 & & & \\
\hline & 2 & 1986 & 0.080 & 6.3 & 93.7 & & & \\
\hline & 2 & 1987 & 0.083 & 6.7 & 93.4 & & & \\
\hline & 2 & 1988 & 0.089 & 8.0 & 92.0 & & & \\
\hline & 2 & 1989 & 0.088 & 7.2 & 92.8 & & & \\
\hline & 2 & 1990 & 0.091 & 7.5 & 92.5 & & & \\
\hline & 2 & 1991 & 0.098 & 9.1 & 90.9 & & & \\
\hline & 2 & 1992 & 0.108 & 11.6 & 88.4 & & & \\
\hline & 2 & 1993 & 0.112 & 12.9 & 87.1 & & & \\
\hline & 2 & 1994 & 0.117 & 14.7 & 85.3 & & & \\
\hline & 2 & 1995 & 0.120 & 17.3 & 82.7 & & & \\
\hline \multirow[t]{13}{*}{ China } & 2 & 1983 & 0.079 & 78.1 & 21.9 & urban/rural & \multirow{13}{*}{$\begin{array}{l}\text { Kanbur and } \\
\text { Zhang (1999) }\end{array}$} & \multirow{13}{*}{$\begin{array}{l}\text { regional data on } \\
\text { per capita } \\
\text { consumption } \\
\text { expenditure }\end{array}$} \\
\hline & 2 & 1984 & 0.076 & 75.8 & 24.2 & & & \\
\hline & 2 & 1985 & 0.075 & 77.0 & 23.1 & & & \\
\hline & 2 & 1986 & 0.080 & 74.5 & 25.5 & & & \\
\hline & 2 & 1987 & 0.083 & 74.8 & 25.2 & & & \\
\hline & 2 & 1988 & 0.089 & 74.7 & 25.3 & & & \\
\hline & 2 & 1989 & 0.088 & 73.3 & 26.7 & & & \\
\hline & 2 & 1990 & 0.091 & 74.9 & 25.1 & & & \\
\hline & 2 & 1991 & 0.098 & 75.5 & 24.5 & & & \\
\hline & 2 & 1992 & 0.108 & 73.5 & 26.5 & & & \\
\hline & 2 & 1993 & 0.112 & 75.1 & 24.9 & & & \\
\hline & 2 & 1994 & 0.117 & 73.3 & 26.7 & & & \\
\hline & 2 & 1995 & 0.120 & 70.7 & 29.3 & & & \\
\hline \multirow[t]{3}{*}{ China } & 2 & 1994 & 0.330 & 37.7 & 62.3 & urban/rural & \multirow[t]{3}{*}{ Lee (2000) } & \multirow{3}{*}{$\begin{array}{l}1994 \text { county/city } \\
\text { data on per capita } \\
\text { consumption }\end{array}$} \\
\hline & 3 & 1994 & 0.330 & 28.0 & 72.0 & zone & & \\
\hline & 26 & 1994 & 0.330 & 36.8 & 63.2 & region & & \\
\hline \multirow[t]{3}{*}{ China } & 2 & 1994 & 0.390 & 25.8 & 74.2 & urban/rural & \multirow[t]{3}{*}{ Lee (2000) } & \multirow{3}{*}{$\begin{array}{l}1994 \text { county/city } \\
\text { data on per capita } \\
\text { GVIAO }\end{array}$} \\
\hline & 3 & 1994 & 0.390 & 39.0 & 61.0 & zone & & \\
\hline & 26 & 1994 & 0.390 & 51.5 & 48.5 & region & & \\
\hline \multirow{6}{*}{ China } & & & & & & county within: & \multirow{6}{*}{$\begin{array}{l}\text { Cheng Y. } \\
(1996)\end{array}$} & \multirow{6}{*}{$\begin{array}{l}1994 \text { household } \\
\text { survey data on per } \\
\text { capita income }\end{array}$} \\
\hline & 4 & 1994 & 0.141 & 24.0 & 76.0 & Jilin & & \\
\hline & 4 & 1994 & 0.070 & 20.0 & 80.0 & Shandong & & \\
\hline & 4 & 1994 & 0.075 & 9.0 & 91.0 & Sichuan & & \\
\hline & 4 & 1994 & 0.232 & 9.0 & 91.0 & Guangdong & & \\
\hline & 4 & 1994 & 0.139 & 4.0 & 96.0 & Jiangxi & & \\
\hline China & 5 & 1994 & 0.222 & 39.0 & 61.0 & province & & \\
\hline
\end{tabular}




\begin{tabular}{|c|c|c|c|c|c|c|c|c|}
\hline \multirow[t]{4}{*}{ Ecuador } & 3 & 1994 & na & 0.0 & 100.0 & rural region & \multirow{4}{*}{$\begin{array}{l}\text { Elbers et al. } \\
(2002)\end{array}$} & \multirow{4}{*}{$\begin{array}{l}1994 \text { estimated } \\
\text { household data on } \\
\text { per capita } \\
\text { expenditure }\end{array}$} \\
\hline & 21 & 1994 & na & 1.3 & 98.7 & rural province & & \\
\hline & 195 & 1994 & na & 5.9 & 94.1 & rural Canton & & \\
\hline & 915 & 1994 & na & 14.1 & 85.9 & rural parroquia & & \\
\hline \multirow[t]{4}{*}{ Ecuador } & 5 & 1994 & na & 6.6 & 93.4 & urban region & \multirow{4}{*}{$\begin{array}{l}\text { Elbers et al. } \\
(2002)\end{array}$} & \multirow{4}{*}{$\begin{array}{l}1994 \text { estimated } \\
\text { household data on } \\
\text { per capita } \\
\text { expenditure }\end{array}$} \\
\hline & 19 & 1994 & na & 7.3 & 92.7 & urban province & & \\
\hline & 87 & 1994 & na & 8.6 & 91.4 & urban Canton & & \\
\hline & 664 & 1994 & na & 23.3 & 76.7 & urban zonas & & \\
\hline \multirow[t]{5}{*}{ Finland } & 4 & 1971 & 0.127 & 12.5 & 87.5 & region & \multirow{5}{*}{$\begin{array}{l}\text { Loikkanen et } \\
\text { al. (2002) }\end{array}$} & \multirow{5}{*}{$\begin{array}{l}\text { household data on } \\
\text { per capita income }\end{array}$} \\
\hline & 4 & 1981 & 0.076 & 6.3 & 93.7 & & & \\
\hline & 4 & 1990 & 0.069 & 7.6 & 92.4 & & & \\
\hline & 4 & 1993 & 0.075 & 7.3 & 92.7 & & & \\
\hline & 4 & 1998 & 0.104 & 4.4 & 95.6 & & & \\
\hline \multirow[t]{2}{*}{ Ghana } & 3 & 1996 & 0.269 & 29.6 & 70.4 & residence area & \multirow{2}{*}{$\begin{array}{l}\text { Jacqueline } \\
(2002)\end{array}$} & \multirow{2}{*}{$\begin{array}{l}\text { household data on } \\
\text { per capita } \\
\text { consumption }\end{array}$} \\
\hline & 6 & 1996 & 0.269 & 29.1 & 70.9 & residence area & & \\
\hline \multirow[t]{4}{*}{ Greece } & 2 & 1974 & 0.196 & 10.1 & 89.9 & urban/rural & \multirow{4}{*}{$\begin{array}{l}\text { Tsakloglou } \\
\text { (1993) }\end{array}$} & \multirow{4}{*}{$\begin{array}{l}\text { household data on } \\
\text { per capita } \\
\text { consumption }\end{array}$} \\
\hline & 2 & 1982 & 0.160 & 9.3 & 90.7 & & & \\
\hline & 9 & 1974 & 0.196 & 12.4 & 87.6 & region & & \\
\hline & 9 & 1982 & 0.159 & 8.7 & 91.3 & & & \\
\hline \multirow[t]{6}{*}{ India } & 17 & 1977 & 0.277 & 5.0 & 95.0 & region & \multirow{6}{*}{$\begin{array}{l}\text { Mishra and } \\
\text { Parikh (1992) }\end{array}$} & \multirow{6}{*}{$\begin{array}{l}\text { household data on } \\
\text { per capita } \\
\text { consumption }\end{array}$} \\
\hline & 17 & 1983 & 0.182 & 5.3 & 94.7 & & & \\
\hline & 17 & 1977 & 0.214 & 10.9 & 89.1 & rural region & & \\
\hline & 17 & 1983 & 0.164 & 8.2 & 91.8 & & & \\
\hline & 17 & 1977 & 0.219 & 1.8 & 98.2 & urban region & & \\
\hline & 17 & 1983 & 0.180 & 3.4 & 96.6 & & & \\
\hline \multirow[t]{3}{*}{ Indonesia } & 2 & 1987 & 0.228 & 22.3 & 77.7 & urban/rural & \multirow{3}{*}{$\begin{array}{l}\text { Akita et al. } \\
\text { (1999) }\end{array}$} & \multirow{3}{*}{$\begin{array}{l}\text { household data on } \\
\text { per capita } \\
\text { expenditure }\end{array}$} \\
\hline & 2 & 1990 & 0.223 & 22.0 & 78.0 & & & \\
\hline & 2 & 1993 & 0.239 & 25.2 & 74.8 & & & \\
\hline \multirow[t]{3}{*}{ Indonesia } & 27 & 1987 & 0.232 & 15.1 & 84.9 & province & Akita et al. & household data on \\
\hline & 27 & 1990 & 0.227 & 15.0 & 85.0 & & (1999) & per capita \\
\hline & 27 & 1993 & 0.243 & 17.3 & 82.7 & & & expenditure \\
\hline Indonesia & 26 & 1990 & 0.223 & 13.0 & 87.0 & province & Tadjoeddin & household data on \\
\hline & 26 & 1993 & 0.239 & 15.0 & 85.0 & & $(2003)$ & per capita \\
\hline & 26 & 1996 & 0.216 & 21.0 & 79.0 & & & expenditure \\
\hline & 26 & 1998 & 0.172 & 22.0 & 78.0 & & & \\
\hline & 26 & 1999 & 0.190 & 21.0 & 79.0 & & & \\
\hline & 26 & 2002 & 0.233 & 15.0 & 85.0 & & & \\
\hline Madagascar & 6 & 1993 & N/A & 4.8 & 95.2 & rural faritany & Elbers et al. & 1993 estimated \\
\hline & 104 & 1993 & N/A & 15.4 & 84.6 & $\begin{array}{l}\text { rural } \\
\text { fivondrona }\end{array}$ & (2002) & $\begin{array}{l}\text { household data on } \\
\text { per capita }\end{array}$ \\
\hline & 1117 & 1993 & N/A & 18.1 & 81.9 & rural firaisana & & expenditure \\
\hline Madagascar & 6 & 1993 & N/A & 7.7 & 92.3 & urban faritany & Elbers et al. & 1993 estimated \\
\hline & 103 & 1993 & N/A & 21.7 & 78.3 & $\begin{array}{l}\text { urban } \\
\text { fivondrona }\end{array}$ & $(2002)$ & $\begin{array}{l}\text { household data on } \\
\text { per capita }\end{array}$ \\
\hline & 131 & 1993 & N/A & 23.2 & 76.8 & urban firaisana & & expenditure \\
\hline Mozambique & 424 & 1996 & N/A & 22.0 & 78.0 & $\begin{array}{l}\text { administrative } \\
\text { post }\end{array}$ & $\begin{array}{l}\text { Elbers et al. } \\
\text { (2002) }\end{array}$ & $\begin{array}{l}\text { estimated } \\
\text { household data on }\end{array}$ \\
\hline & 146 & 1996 & N/A & 18.4 & 81.6 & district & & per capita \\
\hline & 11 & 1996 & N/A & 9.3 & 90.7 & province & & expenditure \\
\hline
\end{tabular}




\begin{tabular}{|c|c|c|c|c|c|c|c|c|}
\hline \multirow[t]{5}{*}{ Phillipines } & 2 & 1985 & 0.282 & 17.2 & 82.8 & urban/rural & \multirow{5}{*}{$\begin{array}{l}\text { Balisacan and } \\
\text { Fuwa (2003) }\end{array}$} & \multirow{5}{*}{$\begin{array}{l}\text { family income and } \\
\text { expenditure survey } \\
\text { data on per capita } \\
\text { expenditure }\end{array}$} \\
\hline & 2 & 1988 & 0.264 & 16.6 & 83.4 & & & \\
\hline & 2 & 1991 & 0.306 & 16.3 & 83.7 & & & \\
\hline & 2 & 1994 & 0.260 & 15.6 & 84.4 & & & \\
\hline & 2 & 1997 & 0.303 & 17.5 & 82.5 & & & \\
\hline \multirow[t]{5}{*}{ Phillipines } & 13 & 1985 & 0.282 & 15.4 & 84.6 & region & \multirow{5}{*}{$\begin{array}{l}\text { Balisacan and } \\
\text { Fuwa (2003) }\end{array}$} & \multirow{5}{*}{$\begin{array}{l}\text { family income and } \\
\text { expenditure survey } \\
\text { data on per capita } \\
\text { expenditure }\end{array}$} \\
\hline & 13 & 1988 & 0.264 & 13.0 & 87.0 & & & \\
\hline & 13 & 1991 & 0.306 & 17.6 & 82.4 & & & \\
\hline & 13 & 1994 & 0.260 & 13.5 & 86.5 & & & \\
\hline & 13 & 1997 & 0.303 & 15.1 & 84.9 & & & \\
\hline \multirow[t]{6}{*}{ Russia } & 77 & 1994 & 0.297 & 25.0 & 75.0 & region & \multirow{6}{*}{$\begin{array}{l}\text { Yemtsov } \\
(2002)\end{array}$} & \multirow{6}{*}{$\begin{array}{l}\text { household budget } \\
\text { survey data on per } \\
\text { capita income }\end{array}$} \\
\hline & 77 & 1995 & 0.282 & 27.0 & 73.0 & & & \\
\hline & 77 & 1996 & 0.316 & 26.0 & 74.0 & & & \\
\hline & 77 & 1997 & 0.337 & 23.0 & 77.0 & & & \\
\hline & 77 & 1998 & 0.314 & 28.0 & 72.0 & & & \\
\hline & 77 & 1999 & 0.329 & 31.0 & 69.0 & & & \\
\hline \multirow[t]{2}{*}{ Switzerland } & 3 & 1982 & 0.136 & 0.2 & 99.8 & & \multirow{2}{*}{$\begin{array}{l}\text { Ernst et al. } \\
(2000)\end{array}$} & \multirow{2}{*}{$\begin{array}{l}\text { household data on } \\
\text { per capita income }\end{array}$} \\
\hline & 3 & 1992 & 0.159 & 0.6 & 99.4 & & & \\
\hline
\end{tabular}

Table 1B: Spatial decomposition of $\mathrm{E}_{0}$ : earnings

\begin{tabular}{|c|c|c|c|c|c|c|c|c|}
\hline Country & $\begin{array}{l}\text { No. of } \\
\text { groups }\end{array}$ & Year & $\begin{array}{c}\text { Total } \\
\text { inequality }\end{array}$ & $\begin{array}{c}\text { Between } \\
\%\end{array}$ & $\begin{array}{c}\text { Within } \\
\%\end{array}$ & Category & Source & Remarks \\
\hline \multirow[t]{4}{*}{ UK } & 12 & 1979 & 0.260 & 1.0 & 99.0 & \multirow[t]{4}{*}{ region } & \multirow[t]{4}{*}{ Parker (1999) } & \multirow{4}{*}{$\begin{array}{l}\text { FES data on } \\
\text { employee income }\end{array}$} \\
\hline & 12 & 1985 & 0.310 & 1.8 & 98.2 & & & \\
\hline & 12 & 1991 & 0.320 & 2.5 & 97.5 & & & \\
\hline & 12 & $1994 / 5$ & 0.330 & 2.4 & 97.6 & & & \\
\hline \multirow[t]{4}{*}{$\overline{\mathrm{UK}}$} & 12 & 1979 & 1.850 & 2.5 & 97.5 & \multirow[t]{4}{*}{ region } & \multirow[t]{4}{*}{ Parker (1999) } & \multirow{4}{*}{$\begin{array}{l}\text { FES data on self- } \\
\text { employment income }\end{array}$} \\
\hline & 12 & 1985 & 0.650 & 3.0 & 97.0 & & & \\
\hline & 12 & 1991 & 0.780 & 9.8 & 90.2 & & & \\
\hline & 12 & $1994 / 5$ & 1.520 & 3.0 & 97.0 & & & \\
\hline \multirow[t]{4}{*}{ UK } & 11 & 1975 & 0.095 & 3.2 & 96.8 & \multirow[t]{4}{*}{ region } & \multirow[t]{4}{*}{ Dickey (2001) } & New Earnings \\
\hline & 11 & 1980 & 0.094 & 4.3 & 95.7 & & & Survey (individual) \\
\hline & 11 & 1991 & 0.133 & 6.8 & 93.2 & & & data \\
\hline & 11 & 1995 & 0.152 & 7.2 & 92.8 & & & \\
\hline \multirow[t]{2}{*}{$\overline{\mathrm{UK}}$} & 11 & 1991 & 0.213 & 12.2 & 87.8 & \multirow[t]{2}{*}{ region } & \multirow[t]{2}{*}{ Dickey (2001) } & British Household \\
\hline & 11 & 1996 & 0.286 & 7.7 & 92.3 & & & $\begin{array}{l}\text { Panel Survey } \\
\text { (individual) data }\end{array}$ \\
\hline
\end{tabular}


Table 2. Correlation between shares of the between-group component

\begin{tabular}{cccc}
\hline & $\mathrm{E}_{1}$ & $\mathrm{E}_{2}$ & Gini \\
\hline $\mathrm{E}_{0}$ & 0.98 & 0.83 & 0.65 \\
$\mathrm{E}_{1}$ & & 0.98 & 0.64 \\
$\mathrm{E}_{2}$ & & & 0.75 \\
\hline
\end{tabular}

Table 3. Estimation results

\begin{tabular}{|c|c|c|c|c|}
\hline Variable & $\begin{array}{l}\text { Coefficient } \\
\text { estimate }\end{array}$ & T-ratio & $\begin{array}{c}\text { Significance } \\
\text { level }\end{array}$ & $\begin{array}{l}\text { Box-Cox } \\
\text { elasticity }\end{array}$ \\
\hline number of groups & 0.13 & 3.65 & 0.00 & 0.17 \\
\hline \multicolumn{5}{|l|}{ dummy for } \\
\hline $\mathrm{E}_{1}$ & -0.31 & -1.12 & 0.26 & -0.03 \\
\hline $\mathrm{E}_{2}$ & -0.39 & -0.50 & 0.62 & -0.00 \\
\hline Gini & 3.51 & 8.20 & 0.00 & 0.13 \\
\hline \multicolumn{5}{|l|}{ dummy for } \\
\hline earnings & -1.50 & -5.09 & 0.00 & -0.13 \\
\hline ‘urban-rural & 1.73 & 4.74 & 0.00 & 0.11 \\
\hline constant & 2.63 & 12.01 & 0.00 & 1.24 \\
\hline $\mathrm{R}^{2}=0.39$ & \multicolumn{4}{|c|}{ Sample size $=185$} \\
\hline
\end{tabular}




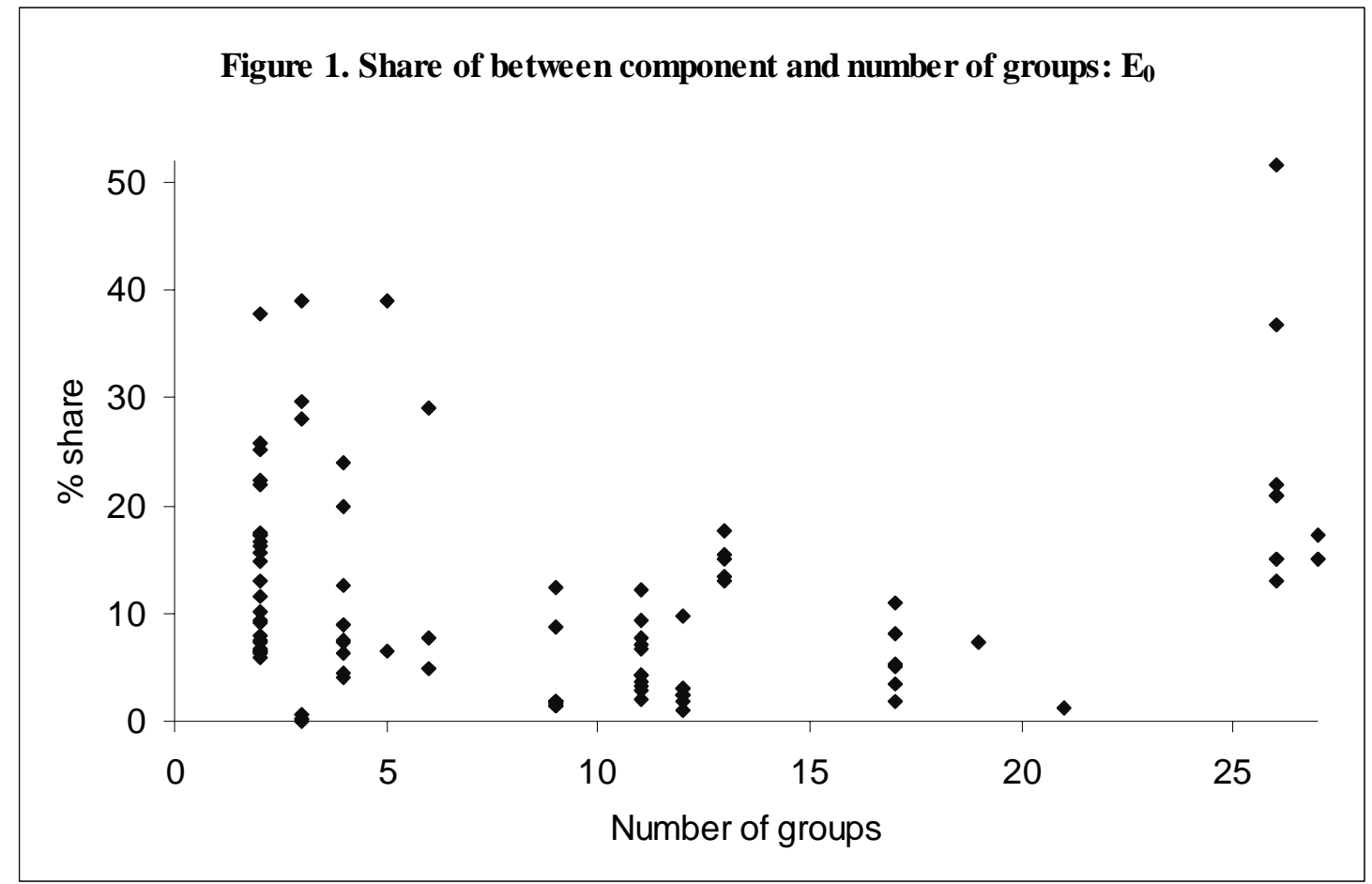

Figure 2. Share of between component and number of groups: $E_{1}$

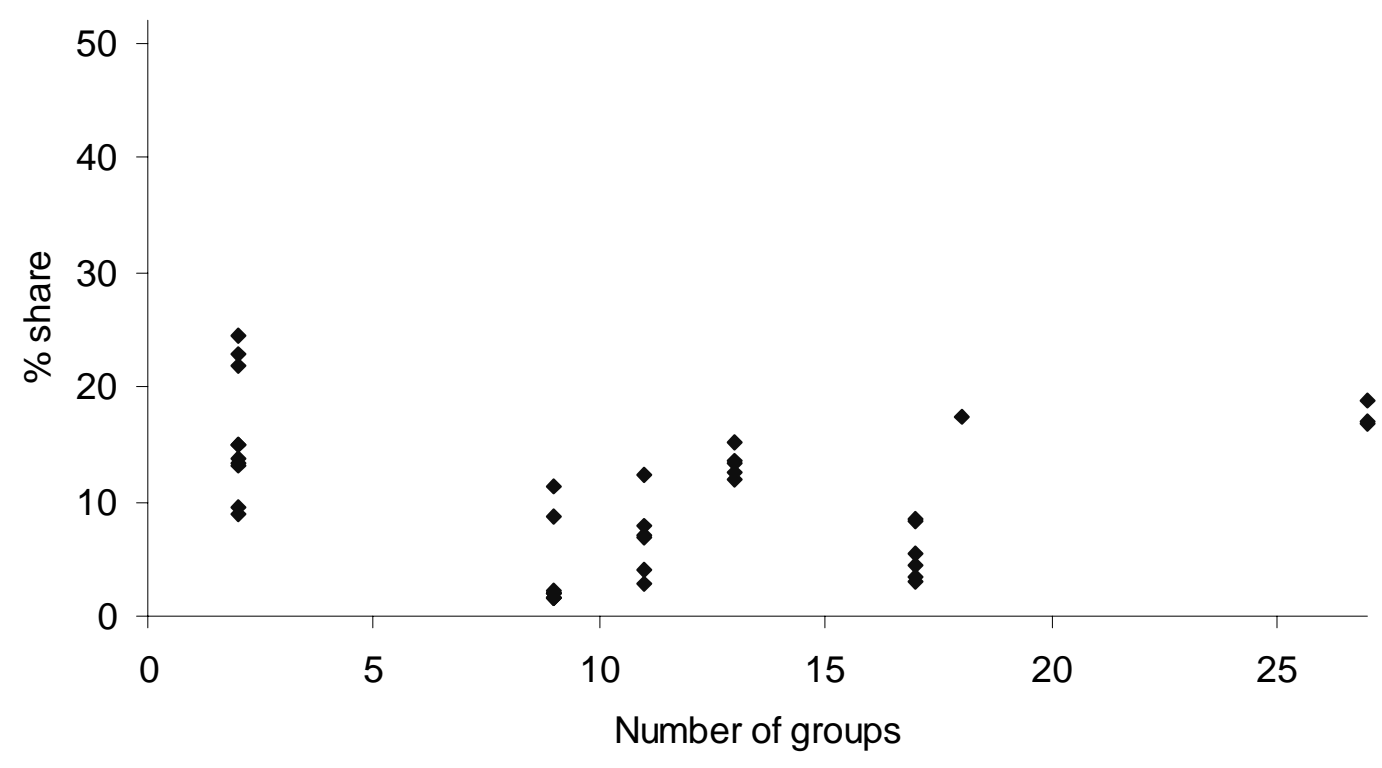



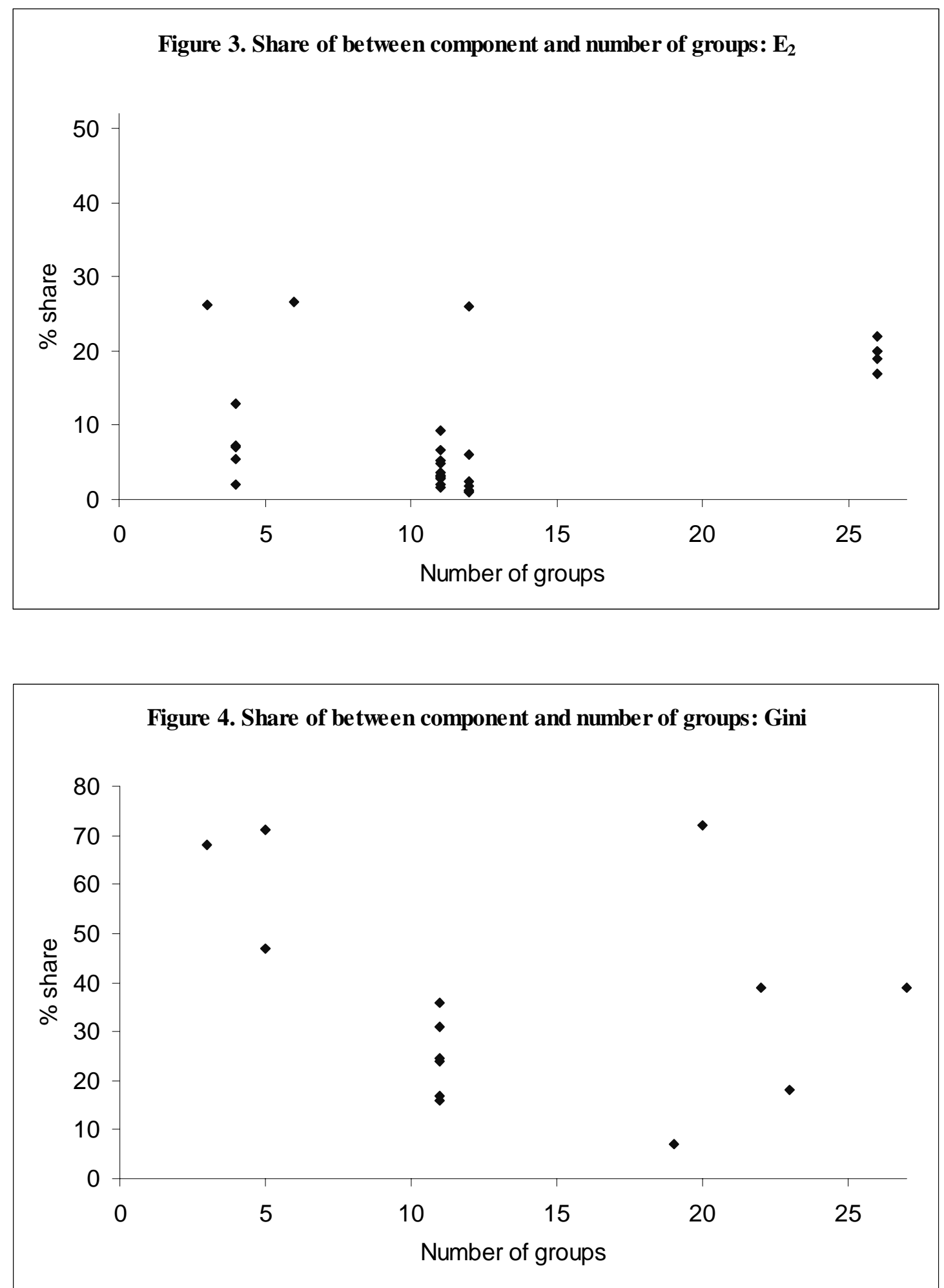